\title{
Energy in Growth Accounting and the Aggregation of Capital and Output
}

\author{
Reiner Kümmel ${ }^{1} \cdot$ Dietmar Lindenberger $^{2}$
}

Received: 12 June 2019 / Revised: 21 January 2020 / Accepted: 24 February 2020 / Published online: 18 March 2020

(c) The Author(s) 2020

\begin{abstract}
We review the physical aggregation of value added and capital in terms of work performance and information processing and its relation to the deflated monetary time series of output and capital. In growth accounting it complements the time series of labor and energy, measured in hours worked per year and kilowatt-hours consumed per year, respectively. This aggregation is the conceptual basis on which those energy-dependent production functions have been constructed that reproduce economic growth of major industrial countries in the 20th century with small residuals and output elasticities that are for energy much larger and for labor much smaller than the cost shares of these factors. Accounting for growth in such a way, which deviates from that of mainstream economics, may serve as a first step towards integrating the First and the Second Law of Thermodynamics into economics.
\end{abstract}

Keywords Aggregation $\cdot$ Cost-share theorem $\cdot$ Economic growth $\cdot$ Energy $\cdot$ Entropy $\cdot$ Output elasticities

\section{Introduction}

Recently, Fix (2019) argued "that the growth of real GDP is not worth explaining". This verdict is based on the following observations: (1) The output and the capital stock of a country's economy are aggregated and measured monetarily by the national accounts of the country's statistical offices. (2) The prices of the goods and services that make up the output-which is the GDP (or parts thereof, if one considers a sector of the economy) - are unstable over time because of inflation and subjective decisions. The latter concern corrections for inflation and quality changes of commodities. (3) The GDP ignores unpaid domestic work, environmental degradation, and social "bads".

Interestingly, in the paragraph preceding the verdict, the author states that the field of growth accounting has tended to ignore the role of energy and continues: "Ecological and biophysical economists have devoted significant efforts in fixing this situation. Many studies now exist that analyze the role that energy plays in driving the growth of real GDP (Ayres

Reiner Kümmel

kuemmel@physik.uni-wuerzburg.de

1 Institute for Theoretical Physics und Astrophysics, University of Würzburg, 97074 Würzburg, Germany

2 Institute of Energy Economics, University of Cologne, 50827 Cologne, Germany and Warr 2005, 2010; Hall et al. 2001; Kummel 1982, 1989; Kummel et al. 1985, 2000)". Those of the cited publications, whose (partly flawed) references are explicitly reproduced here, do precisely what B. Fix criticizes: Elucidate the role of energy in the generation of output via growth accounting based on energy-dependent production functions with monetary aggregation of capital and output. Obviously, there is need for a reappraisal of the biophysical reasoning and the methods that led to the macroscopic production functions in question. This paper tries to respond to that need.

\section{The Importance of Understanding the Growth of GDP}

Before addressing aggregation in growth accounting let us recall why it is important to look into the growth of GDP or parts thereof.

The gross domestic product (GDP) sums up all salaried economic activities that produce the output of value added within a country. It is measured in monetary units. It includes services that mitigate the damages from accidents, crime, pollution, and other harmful occurrences, such as the abuse of drugs and alcohol, and it excludes the domestic care of people for their children and parents, housekeeping by family members, and community services. Thus, it does not 
measure the overall well-being of a country's population. This is common knowledge. Nevertheless, the growth of GDP and the growth of the output of economic sectors, such as agriculture, industry, and services, are of eminent political and social importance. Studying "The Central Role of Energy in Urban Transition" (Burger et al. 2019) points out that recent "research ...suggests that increasing returns in Gross Domestic Product ...can be attributed to the enhanced networks facilitated by the "buzz of the city' ..."; they "used GDP in constant US\$ because it is ...highly correlated with other measures of economic well being, including the Human Development Index ....'. People go where the action is. They appreciate economic activities measured by GDP, notwithstanding their negative side effects. One important reason is that economic activities provide jobs, especially when economic growth opens up new fields whose jobs make up for the traditional jobs that are lost to progress in automation. Thus, voters tend to reelect governments that rule in times of growth, and oust the ones they hold responsible for economic recessions. Migrants from less industrialized parts of the world with low GDP/capita risk their lives to get into highly industrialized countries with high GDP/capita.

The importance of understanding economic growth quantitatively showed dramatically in the political and social impacts the downturns and upswings of GDP had as a consequence of the first and the second oil-price shock between 1973 and 1981. Since then, growth models with restrictions concerning energy (Ströbele 1982), and production functions involving energy, have become part of the economic theory of natural resources (Eichhorn et al. 1982).

\section{Work Performance and Information Processing}

Since the publication of "The Limits to Growth" by Meadows et al. (1972), the aim of sustaining that sort of economic growth the first two-thirds of the 20th century had seen in the highly industrialized countries has been questioned increasingly. Irrefutable are the objections that are based on the "constitution of the universe", as one may call the First and the Second Law of Thermodynamics. Combined these two laws state: Nothing happens in the world without energy conversion and entropy production. They govern the evolution of the stars, of life on Earth, and of agricultural and industrial production. Had these laws been taken into account by textbook economics, there were no need for ecological and biophysical economics.

Entropy production, which is always coupled to energy conversion and which involves emissions that may disturb the environment, was a topic of "Ecological Economics", initially. Later, thermodynamics became less important, and topics and methods of the field moved closer to those of mainstream neoclassical economics.

Work performance (driven by the energy from ATP $\rightarrow$ ADP conversion) and (genetic/neural) information processing in the living species, as well as work performance and information processing in the capital stock, which is handled by labor and activated by fossil, nuclear, and renewable energies in industrial economies, pertain to the realm of biophysical economics. These operations are the physical basis from which the appropriate physical units for the aggregation of output and production factors can be derived. This, and how the physical units of output and capital can be related to deflated monetary units, is shown subsequently in some more detail than in prior publications. In so doing we follow Kümmel (2011). One may consider this as a response to the well-known objections against monetary aggregation of output and capital that have been raised since the times of the "Cambridge capital controversy" (Robinson 1971). It provides the conceptual foundation for the macroscopic, energy-dependent production functions whose economic weights of energy and labor turn out to be at variance with neoclassical economics.

Felipe and Fisher (2003), and others as well, include macroscopic production functions in their critique of the neoclassical theory. Heun et al. (2017) tell "cautionary tales for policy making using aggregate production functions". And there are scholars like Proops et al. (1993), who prefer to model economic activities by input-output analyses, where microscopic production functions for firms may come into play.

Anyway, the energy-dependent production functions discussed in the next section are relatively simple instruments from the mathematical toolkit of economics. Nevertheless, used properly in growth accounting and optimization subject to constraints, they reveal the crux of textbook economics: the underestimation of energy's high productive power. Combining energy's big economic weight with the coupling of energy conversion to entropy production and the latter's environmental impacts is one of the big challenges for a theory of economic growth that explores paths towards sustainability. Let us consider the units proposed for (and used in) first steps towards such a theory.

\section{Assumption 1}

- The monetary value of goods is the higher the more physical work must be performed and the more information must be processed in the production of the good or the service. $^{1}$

\footnotetext{
1 This is not meant to contradict subjective value theory according to which value is ultimately derived from individual preferences and willingness-to-pay, i.e., demand. Rather, we assume that the production of goods and services follows demand. If demand and production changes, and this changes the monetary evaluation of the required work performance and information processing, then this implies
} 
- The monetary valuation of work performance and information processing may differ for the different components of output. However, the average, taken over all components, stays constant in good approximation during time intervals that are shorter than the characteristic times for innovation diffusion.

- Correspondingly, the monetary valuation of capital goods depends on their capacities to perform physical work and process information, and the sum over all averages is the monetary value of the capital stock.

The following considerations on aggregation of output and capital constitute physically based measurement prescriptions that are important conceptually. They respond to the Cambridge controversy (Robinson 1953, 1971), which criticized that output and capital could not be measured independently. Subsequently we show that physically based prescriptions for the measurement of output and capital are in fact possible, even if only in principle. While these prescriptions are related, by definition, to monetary units for the sake of practicability, see below, the important point remains that the measurement of output and capital can fundamentally be based on physical terms. Having in mind that the production process is, of course, a physical process based on work performance and information processing in the capital stock, this is the logical consequence for an engineering foundation of the macroeconomic production function.

\section{Aggregation of Output}

We choose the well-known kilowatt-hour $(\mathrm{kWh})$ as the energetic unit for measuring the work performed in the production of a good or a service. The kilobit $(\mathrm{kB})$ is the convenient unit for measuring the associated quantity of processed information.

Since there are no statistics that measure output in such physical units, one has to relate work performance and information processing to the time series of output in deflated monetary units provided by the national accounts. For this, a fictitious unit called Mark is introduced as a dummy for any really existing monetary unit. Aggregation for a given economic system proceeds as follows.

Footnote 1 (continued)

structural changes in the production system, which will be reflected by time-changing technology parameters in the production function, see "Energy-Dependent Production Functions" section. This may also include changes in the role and share of products with abnormal price elasticity (e.g., Veblen goods, whose demand increases with increasing price), or products associated with positive externalities (e.g., software, positive network effects, or knowledge spill overs).
1. Subdivide the monetarily measured output $Y_{\text {mon }}(t)$ at time $t$ in $M(t) \gg 1$ parts $Y_{i \text {,mon }}$ that all have the same monetary value $\mu$ Mark. Thus,

$Y_{\mathrm{mon}}(t)=\sum_{i=1}^{M} Y_{i, \mathrm{mon}}=M(t) \mu \mathrm{Mark}$

2. The physical work performed in the production of $Y_{i \text {,mon }}$ can be measured (a) by the enthalpy $E$ of the primary energy carriers ${ }^{2}$ that are fed into the processes that produce $Y_{i, \text { mon }}$; it includes the losses from entropy production; or (b) by the exergy that works directly on the materials that are used in the processes. Exergy is the useful component of an energy quantity $E$. It can be converted into any other convenient energy form. It is not conserved. Rather, the First Law of Thermodynamics on energy conservation states:

Energy $\equiv$ Exergy + Anergy $=$ Constant

Anergy, generated inevitably by entropy production, is completely useless. Whenever something happens, entropy is produced and anergy grows at the expense of exergy. In this sense, "energy consumption" really means "exergy" consumption. ${ }^{3}$ An example for anergy is heat dumped into the environment. Many examples for exergy are given by Fricke and Borst (1984), some are reproduced in Kümmel (2011). In principle, at sufficiently high process temperatures, all fossil and nuclear fuels are $100 \%$ exergy, and so is solar radiation. Whether one uses primary energy $E$ or exergy as a measure of the physical work employed in production depends on the availability and reliability of the corresponding data. Here, as in Lindenberger et al. (2017) and elsewhere, we use primary energy data. (They are usually given in enthalpy units like Joule, where 1 kilowatt-hour $=3.6$ Megajoules.) The use of exergy data, such as the ones calculated by Ayres et al. (2003), will be discussed in the next section.

We define:

$W_{i}=$ number of $\mathrm{kWh}$ of primary energy consumed in the production of $Y_{i \text {,mon }}$.

$V_{i}=$ number of kilobits processed in the production of $Y_{i \text { mon }}$.

Machine standards can be established for the measurements of the $W_{i}$ and $V_{i}$ embodied in the goods and services by considering them as being produced (hypo-

\footnotetext{
${ }^{2}$ Enthalpy $E$ measures the heating value of fuels in precisely defined combustion processes.

3 A thorough understanding of energy and entropy, and their importance for industrial economies, can be obtained, e.g., from Baehr (1964), Reif (1965), Kluge and Neugebauer (1993), and van Gool (1998).
} 
thetically) in fully automated factories and offices. The studies on artificial intelligence are helpful for that.

3. The physical quantity $Y_{\text {phys }}$ of value added in the system is defined as

$Y_{\text {phys }}(t)=\sum_{i=1}^{M} Y_{i, \text { phys }} \equiv \sum_{i=1}^{M} W_{i} \cdot \mathrm{kWh} \cdot V_{i} \cdot \mathrm{kB}$.

According to the definitions in step 1 the monetary value of $Y_{i \text {,phys }}$ is $\mu$ Mark.

The physical unit of value added in terms of work performance and information processing has been given the name ENIN (as a short hand for "ENergy and INformation"), and it is defined by the average

$\mathrm{ENIN} \equiv \frac{1}{M} \sum_{i=1}^{M} W_{i} \cdot \mathrm{kWh} \cdot V_{i} \cdot \mathrm{kB}=\zeta \mathrm{kWh} \cdot \mathrm{kB}$,

where

$\zeta \equiv \frac{1}{M} \sum_{i=1}^{M} W_{i} \cdot V_{i}$

Thus, the total output of an economic system in physical units is

$Y_{\text {phys }}=M \cdot$ ENIN.

The equivalence factor $\zeta$ changes in time $t$, if the monetary valuation of work performance and information processing changes in time in such a way that the numbers $W_{i} \cdot V_{i}$, which correspond to $\mu$, and the rhs of equation (4) become time dependent.

4. From the above equations the relation between monetary and physical output results as

$\frac{Y_{\text {mon }}(t)}{Y_{\text {phys }}(t)}=\frac{M \mu \cdot \text { Mark }}{M \cdot \mathrm{ENIN}}=\frac{\mu}{\zeta} \cdot \frac{\text { Mark }}{\mathrm{kWh} \cdot \mathrm{kB}}$

As long as $\zeta$ stays constant, the monetary $Y_{\text {mon }}$ and its time series are proportional to the physical $Y_{\text {phys }}$ and its time series, aggregated in the technological ENIN units.

5. If one works with dimensionless variables normalized to their magnitudes in a base year at time $t_{0}$, the dimensionless output at time $t$ is

$y(t) \equiv Y(t) / Y_{0}$,

with $Y_{0}=Y\left(t_{0}\right)$. Consequently, the dimensionless physical value added at time $t$ is

$y_{\text {phys }}(t) \equiv \frac{Y_{\text {phys }}(t)}{Y_{\text {phys }}\left(t_{0}\right)}$.

Because of Eq. (6), the monetary output in the base year $t_{0}$ is

$$
Y_{\text {mon }}\left(t_{0}\right)=\frac{\mu}{\zeta_{0}} \cdot \frac{\text { Mark }}{\mathrm{kWh} \cdot \mathrm{kB}} Y_{\text {phys }}\left(t_{0}\right), \quad \zeta_{0} \equiv \zeta\left(t_{0}\right) \text {. }
$$

Combining Eqs. (6), (8), and (9), one sees that the dimensionless time series of monetary output is equal to the dimensionless time series of the physically aggregated output, multiplied by the factor $\frac{\zeta_{0}}{\zeta}$ :

$y_{\text {mon }}(t) \equiv \frac{Y_{\text {mon }}(t)}{Y_{\text {mon }}\left(t_{0}\right)}=\frac{\zeta_{0}}{\zeta} \frac{Y_{\text {phys }}(t)}{Y_{\text {phys }}\left(t_{0}\right)} \equiv \frac{\zeta_{0}}{\zeta} y_{\text {phys }}(t)$.

As long as the equivalence factor $\zeta$ is time independent and equal to $\zeta_{0}$, the dimensionless monetary time series of output is equal to the dimensionless physical time series. If $\zeta$ becomes time dependent, technology parameters of appropriate energy-dependent production functions may change in time. This will be further discussed in the next section.

A summary of the above is that a physical measure of output can be established based on the elementary processes underlying any production, namely work performance and information processing. The corresponding units of measurement are (a weighted sum of) kWh times kBits "spent" in the production process. For practical reasons, since data on work performed and information processed during production are not available, proportionality between the physical units and the statistically available monetary units (in deflated currency) has to be assumed. This proportionality holds by definition, as long as the monetary evaluation of work performance and information processing does not change in time. If this evaluation changes, however, this makes the associated proportionality "constants" time dependent. This is associated with structural changes in the economy and will be modeled by time-changing technology parameters in the production function, see "Energy-Dependent Production Functions" section. We emphasize that the physical units, due to the lack of physical data, do not directly enter the econometrics but are important for conceptual reasons and the interpretation of results.

As (instrumental) capital represents the maximum capacity to produce output per unit time, analogous physical units can be established to aggregate and measure instrumental capital. The corresponding units will be (a weighted sum of) $\mathrm{kW}$ times kBits per second. This is discussed subsequently.

\section{Aggregation of Capital}

The capital stock of an industrial economy consists of all energy conversion devices and information processors and all buildings and installations necessary for their operation and protection. We relate its capacity of performing work and process information to the time series of its deflated monetary values that are published by the national accounts. 
As in the aggregation of output, aggregation of instrumental capital in physical units proceeds in five steps.

1. Subdivide the monetarily measured gross capital stock $K_{\text {mon }}(t)$ at time $t$ in $N(t) \gg 1$ parts $K_{i, \text { mon }}$ that all have the same monetary value $v$ Mark. Thus,

$K_{\text {mon }}=\sum_{i=1}^{N} K_{i, \text { mon }}=N(t) v$ Mark.

2. The capacity of performing work per unit time is measured in kilowatts $(\mathrm{kW})$, and the capacity of processing information per unit time is measured in kilobits per second $(\mathrm{kB} / \mathrm{s})$. We define:

$S_{i}=$ number of kW the capital component $K_{i, \text { mon }}$ is able to perform.

$T_{i}=$ number of $\mathrm{kB} / \mathrm{s}$ the capital component $K_{i, \mathrm{mon}}$ is able to process.

The $S_{i}$ can be obtained from the specifications of the machines, and the $T_{i}$ are given by the number of switching processes that per unit time block or let pass the energy flows in the machines at maximum utilization of $K_{i \text { mon }}$.

3. The physical magnitude of the capital stock, $K_{\text {phys }}$, is defined as

$K_{\text {phys }}=\sum_{i=1}^{N} K_{i, \mathrm{phys}} \equiv \sum_{i=1}^{N} S_{i} \cdot \mathrm{kW} \cdot T_{i} \cdot \mathrm{kB} / \mathrm{s}$.

According to the definitions in step 1 the monetary value of $K_{i, \text { phys }}$ is $v$ Mark.

The physical unit of capital is defined as the average

$\mathrm{ATON} \equiv \frac{1}{N} \sum_{i=1}^{N} S_{i} \cdot T_{i} \cdot \mathrm{kW} \cdot \mathrm{kB} / \mathrm{s}=\kappa \cdot \mathrm{kW} \cdot \mathrm{kB} / \mathrm{s}$,

where

$\kappa \equiv \frac{1}{N} \sum_{i=1}^{N} S_{i} \cdot T_{i}$

It is measured in terms of $\mathrm{kW} \cdot \mathrm{kB} / \mathrm{s}$. We call this unit ATON, short for AuTomatiON, since automation consists in work performance and information processing within the capital stock. (This autonomous production by machines can be seen as opposed to "zero automation", where work is performed and information processed through human hands and brains, e.g., in hand-crafting).

Thus, the capital stock of an economic system in physical units is

$K_{\text {phys }}=N \cdot$ ATON .
The equivalence factor $\kappa$ changes in time $t$, if the monetary valuations of the capacities to perform work and process information change in such a way that the numbers $S_{i} \cdot T_{i}$, which correspond to $v$, and the rhs of Eq. (14) become time dependent.

4. From the above equations, the relation between monetary and physical capital results as

$\frac{K_{\text {mon }}(t)}{K_{\text {phys }}(t)}=\frac{N v \cdot \text { Mark }}{N \cdot \text { ATON }}=\frac{v}{\kappa} \cdot \frac{\text { Mark }}{\mathrm{kW} \cdot \mathrm{kB} / \mathrm{s}}$.

As long as $\kappa$ stays constant, the monetary $K_{\text {mon }}$ and its time series are proportional to the physical $K_{\text {phys }}$ and its time series, aggregated in the technological ATON units.

5. If one uses dimensionless variables, which are normalized to their magnitudes in a base year $t_{0}$, the dimensionless capital stock at time $t$ is

$k(t) \equiv K(t) / K\left(t_{0}\right) \equiv K(t) / K_{0}$.

Consequently, the physical capital stock is

$k_{\text {phys }}(t) \equiv \frac{K_{\text {phys }}(t)}{K_{\text {phys }}\left(t_{0}\right)}$.

Because of (16) the monetary capital stock in the base year $t_{0}$ is

$K_{\text {mon }}\left(t_{0}\right)=\frac{v}{\kappa_{0}} \cdot \frac{\text { Mark }}{\mathrm{kW} \cdot \mathrm{kB} / \mathrm{s}} K_{\text {phys }}\left(t_{0}\right), \quad \kappa_{0} \equiv \kappa\left(t_{0}\right)$.

Combining Eqs. (16), (18), and (19), one sees that the dimensionless time series of monetarily aggregated capital is equal to the dimensionless time series of the physically aggregated capital, multiplied by the factor $\frac{\kappa_{0}}{\kappa}$ :

$k_{\text {mon }}(t) \equiv \frac{K_{\text {mon }}(t)}{K_{\text {mon }}\left(t_{0}\right)}=\frac{\kappa_{0}}{\kappa} \frac{K_{\text {phys }}(t)}{K_{\text {phys }}\left(t_{0}\right)} \equiv \frac{\kappa_{0}}{\kappa} k_{\text {phys }}(t)$.

As long as the equivalence factor $\kappa$ is time independent and equal to $\kappa_{0}$, the dimensionless monetary time series of capital is equal to the dimensionless physical time series. If $\kappa$ becomes time dependent, technology parameters of appropriate energy-dependent production functions may change in time. As in the case of output, this will be further discussed in the next section.

\section{Labor and Energy}

The human contribution to value added consists of routine labor, which is the production factor $L(t)$, and creative actions. The former is measured physically by the hours worked per year by the workforce of the considered economic system (or, less precisely, by the number of employed persons per year). The latter is the impact of ideas, inventions, and value decisions 
on economic evolution; its econometric measurement is indicated in the next section. The production factor energy $E(t)$ is measured quantitatively by the enthalpy of the inputted energy carriers and qualitatively by their exergy. The dimensionless units, normalized to the factor quantities in the base year $t_{0}$, are

$l(t) \equiv L(t) / L\left(t_{0}\right) \equiv L(t) / L_{0}, \quad e(t) \equiv E(t) / E\left(t_{0}\right) \equiv E(t) / E_{0}$.

\section{The Relation Between Output $Y$ and Production Factors $K, L, E$}

Economic growth depends on (a) human decisions concerning the quantities of $K(t), L(t), E(t)$ to be used at time $t$, and (b) the technical cooperation of these factors.

Standard economic assumptions with respect to (a) are optimization of profit or of time-integrated utility. Prices are crucial for that. Forecasting them is difficult, to say the least, and is not our subject. What matters in growth accounting is (b), i.e., the fact that the technical cooperation of capital $K(t)$, labor $L(t)$, and energy $E(t)$ is governed by the causal technical laws that rule the performance of work and the processing of information by the production factors. Therefore, the output, which embodies work performance and information processing, is unequivocally determined by the factors. Mathematically this means that value added $Y$ is a twice-differentiable function $Y(K, L, E ; t)$ of the variables $K, L, E$. All such functions are production functions. The energy-dependent production functions discussed subsequently are state functions of economic systems, just as internal energy, enthalpy, and entropy are state functions of thermodynamic systems. In this sense, they resemble neoclassical production functions. But they are different from them in a fundamental aspect.

\section{Energy-Dependent Production Functions}

An early attempt on describing the growth of GDP with the help of energy-dependent production functions, based on the aggregation by work performance and information processing, developed and employed LinEx functions $Y_{L}(K, L, E ; t)$. There is a family of these functions. They all have energy $E(t)$ as a third production factor, which, like capital $K(t)$ and labor $L(t)$, can be chosen at will by the economic actors within technological constraints. According to them, output $Y$ depends linearly on one of the factors and exponentially on ratios of the three factors. For example, $Y_{L 1}$, which was derived in 1982 with focus on the output of highly industrialized economies, depends linearly on $E$ and exponentially on factor ratios:
For notational simplicity, the time dependence of $K, L, E$ is not written out explicitly. The two service production functions of Lindenberger (2003), describing services that include banking, insurance, trade, retail, and public administration, where digitization and automation also play an increasing role, depend linearly on $L$ and exponentially on factor ratios. A production function which includes the limiting case of a totally digitized and automated economy, which requires massive capital intensity, turns out to depend linearly on $K$ and exponentially on factor ratios (Kümmel et al. 2018). Note that LinEx functions depend on time $t$ implicitly via the time dependence of the production factors $K(t), L(t), E(t)$ and explicitly via the parameters $Y_{0}(t)$, $a(t)$, and $c(t)$. The latter change in time, when human ideas, inventions and value decisions, in short "creativity", influence technological efficiencies, structural changes, and the monetary valuation of work performance and information processing.

The LinEx functions have NOT been designed in conformity with neoclassical textbook economics. Formally, they and their output elasticities are special solutions of the set of differential equations all (twice differentiable, linearly homogeneous) production functions, including energy-dependent Cobb-Douglas and CES functions, must satisfy at a given time $t$. Their three, possibly timedependent parameters are integration constants of the differential equations and are determined by minimizing the sum of squared errors (SSE), using empirically given time series of $Y, K, L, E$. By construction, LinEx functions ignore the fundamental cost-share theorem of neoclassical economics, according to which the output elasticity of a production factor, which gives the productive power of the factor, should be equal to the factor's share in total factor cost. They reproduce observed economic growth in highly industrialized countries with small residuals and yield output elasticities of energy that are much larger than energy's cost share of roughly 5\% (on an OECD average), whereas the output elasticities of labor turn out to be much smaller than labor's cost share of about $70 \%$. This contradicts the cost-share theorem.

Growth accounting with production functions that do observe the cost-share theorem results in large residuals, which bear the name of their discoverer (Solow 1957, 1994). The Solow residuals are attributed to "technological progress", which is a word for what neoclassically weighted production factors cannot explain. To make up for these residuals one has introduced time-dependent "technological progress" functions that multiply the factor-dependent part of the neoclassical production function

$$
Y_{L 1}(K, L, E ; t)=Y_{0}(t) \frac{E}{E_{0}} \exp \left[a(t)\left(2-\frac{L / L_{0}+E / E_{0}}{K / K_{0}}\right)+a(t) c(t)\left(\frac{L / L_{0}}{E / E_{0}}-1\right)\right] \text {. }
$$


and minimize the difference between observed and theoretical growth. Since the measure of ignorance "technological progress" is an unspecified concept for powerful, mysterious economic forces, people also call it "The Holy Grail of Economics".

Critique of the use of prices in growth accounting with neoclassical production functions is justified, because the cost-share theorem is invalid at the factor prices we have known so far. In its derivation from the optimization of profit or time-integrated utility one has disregarded technological constraints on the combinations of capital, labor, and energy. Those constraints are related to capital's utilization and automation. They require that, at a given point in time, (i) capital's degree of utilization, of course depending on capital, labor, and energy, cannot exceed 100\%, and (ii) capital's degree of automation, also depending on capital, labor, and energy, is limited by the maximum, technologically feasible degree of automation, which cannot exceed $100 \%$. These "hard" constraints on capacity utilization and automation (plus additional "soft" constraints related to social laws limiting fire and hire in connection with progress of automation) are by their very nature (potentially) binding. As a consequence, the technological constraints are associated with shadow prices that drive a wedge between the factors' marginal productivities and prices and between the factor's cost shares and their productive powers (output elasticities), as well. In this sense, the cost-share theorem of standard neoclassical economics is invalid, or, to be more precise, has to be generalized by extending it via appropriate inclusion of factor shadow prices (Kümmel and Lindenberger 2014, and references therein). Thus, the role of prices differs in standard neoclassical and generalized growth accounting. In neoclassical production functions, prices enter the monetary aggregation of output and capital, and the economic weights of the production factors are equal to the factors' cost shares. In non-neoclassical production functions, monetary aggregation of output and capital is used, too, but capital, labor, and energy are not weighted by their cost shares. Rather, output elasticities are determined by econometrics. ${ }^{4}$

Lindenberger et al. (2017) describe the foundations of the research on growth accounting without the cost-share

\footnotetext{
${ }^{4}$ Note that our method of estimating production functions econometrically, i.e., estimating their free technology parameters and the resulting output elasticities, does NOT involve optimizing (factor-cost minimizing or profit maximizing) producer behavior. In other words, neither do we assume optimizing behavior, nor is our method inconsistent with it. What we do say, however, is that IF producers optimize in today's REAL world THEN, contrary to standard neoclassical equilibrium modeling, the factors' output elasticities will NOT turn out as being equal to their cost shares. Only if energy prices become so high that the cost-gradients in the cost mountain do no longer point towards the technological barrier "capacity utilization cannot exceed 100\%" (Kümmel and Lindenberger 2014), things will be different.
}

theorem. They present the differential equations for energydependent production functions and the asymptotic boundary conditions for the output elasticities from which LinEx functions result. They point out that the non-negativity constraint on output elasticities, also crucial in SSE minimization, defines the volume in $K, L, E$-space, where LinEx functions are defined. Considering and reproducing economic growth in the USA and Germany between 1960 and 2013, they determine the integration constants of the differential equations, which are technology parameters, i.e., $Y_{0}(t), a(t)$, $c(t)$ in the LinEx function $Y_{L 1}$, Eq. (22). Their time dependence is due to the economic working of the human factor creativity, defined above. Temporal changes of $Y_{0}(t)$ and $a(t)$ are related to temporal changes of $\zeta$ in Eq. (4) and $\kappa$ in Eq. (14), whereas $c(t)$ decreases when the energetic efficiency of the fully utilized capital stock increases; $a(t)$ and $c(t)$ enter the output elasticities of $Y_{L 1}$. In general, given any production function $Y(K, L, E ; t)$, these elasticities are defined as $\alpha \equiv(K / Y)(\partial Y / \partial K)$ for capital, $\beta \equiv(L / Y)(\partial Y / \partial L)$ for labor, $\gamma \equiv(E / Y)(\partial Y / \partial E)$ for energy, and $\delta \equiv(\Delta t / Y)(\partial Y / \partial t)$ for creativity. Computing the output elasticities of $Y_{L 1}$ in each year between 1960 and 2013, Lindenberger et al. (2017) find their time averages $\bar{\alpha}, \bar{\beta}, \bar{\gamma}$, and $\bar{\delta}$ to be as follows: a) for the total economy of the Federal Republic of Germany (FRG), $\bar{\alpha}=0.37, \bar{\beta}=0.19, \bar{\gamma}=0.44$, and $\bar{\delta}=0.22$; b) for the industrial sector of the FRG, $\bar{\alpha}=0.28, \bar{\beta}=0.08, \bar{\gamma}=0.64$, and $\bar{\delta}=0.13$; and c) for the total economy of the USA, $\bar{\alpha}=0.52$, $\bar{\beta}=0.19, \bar{\gamma}=0.29$, and $\bar{\delta}=0.20$. Error bars and statistical quality measures are given in Table $\mathrm{I}^{5}$ of Lindenberger et al. (2017). Thus, energy and creativity account for most of the growth attributed to "technological progress" by neoclassical economics. Energy is pivotal, since its variations in time are essentially responsible for the reproduction of the economic recessions and recoveries in the wake of the two oil-price shocks between 1973 and 1981 and the financial and economic crisis between 2008 and 2010; see Figs. 2-4 of Lindenberger et al. (2017). Creativity is responsible for fine tuning in fitting by SSE minimization. It is of minor importance in the short run, but decisive in the long run, since human ideas, inventions, value decisions may fundamentally change the course of economic evolution. A recent example is the decision of the winners of World War II to let divided Germany reunite.

Energy-dependent Cobb-Douglas functions with output elasticities that are NOT equal to factor shares but are close to the time-averaged LinEx output elasticities also reproduce overall growth, less well than LinEx, though, but also with residuals much smaller than Solow's, especially when applied to the industrial sector; see, e.g., Fig. 7 of Lindenberger et al. (2017). Furthermore, cointegration analyses for

\footnotetext{
5 This table contains a typo in $\bar{\alpha}$ for Germany's industrial sector.
} 
Germany, Japan, and the USA also lead to energy-dependent Cobb-Douglas functions with output elasticities close to the time averages obtained with LinEx (Stresing et al. 2008).

Thus, energy-dependent production functions that disregard the cost-share theorem but rather determine output elasticities econometrically reveal energy as a powerful driver of economic growth. If they include time-dependent technology parameters, as LinEx functions do, they also contain information on changes due to creativity.

Ayres and Warr (2009) also used the LinEx function (22), although in a formally modified form with exergy ("useful work") data instead of primary energy data. "Useful work" is the exergy that works directly from machines on materials plus the physical work performed by animals. ${ }^{6}$ They reproduced economic growth in the USA and Japan between 1900 and 2005 (excluding the years 1941-1948) with rather small residuals. Their output elasticities-especially after 1950 - are for "useful work" much larger and for labor much smaller than the respective cost shares.

An interesting analysis of output composition during economic growth is given by Illig and Schindler (2017). They analyze the changing distribution of wealth in terms of changing sectoral output composition in the economy over time. In particular, they argue that a high "importance" of an economic sector (in the sense of a high elasticity of output with respect to the sector) during economic growth is associated with a decreasing share of this sector. An example would be a decreasing share of money spent for essential commodities like oil or food, leaving an increasing share of money spendable for other goods and services-with a positive effect on economic activity and growth. Note that this consideration refers to the distribution of wealth with respect to sectoral output shares (for what products money is spent), whereas we consider factor input cost shares of capital, labor, and energy, used in the generation of wealth (what costs are associated with the use of the factor inputs). Of course, it has to be recognized that "energy" can play both roles: i) as a factor input (e.g., crude oil inputted into a refinery or electricity driving a manufacturing process) and ii) as a produced output (e.g., gasoline or electricity as final products, outputted by refineries or power plants), and that the specific role of energy depends on the chosen system boundaries of the production system under consideration; in any case sectoral distribution of wealth, on the one hand, and generation of wealth on the other are distinctly different issues. Sectoral distribution is associated with output shares, whereas value generation is associated with factor input cost shares. The above argument of Illig and Schindler

\footnotetext{
6 The first LinEx study of Ayres and Warr (2001) with "useful work" data and constant technology parameters was done for the USA from 1900 to 1998.
}

(2017) (that the output share of important sectors is shrinking during economic growth) relates to the former, whereas the invalidity of the cost-share theorem, addressed by us and others, relates to the latter. The complementarity of the two issues may be illustrated by the following example. An economy may include an energy-intensive industrial sector plus an expanding service sector. The expansion of the service sector may decrease the energy intensity of the total economy and may be associated with both a decreasing output share of energy (e.g., a smaller share of money spent for gasoline and electricity) and a decreasing factor input cost share of energy in the total economy (since, through the expanding service sector, the economy gets less energyintensive, and more labor-intensive). At the same time, the factor input cost share of energy may well be exceeded by the output elasticity of energy, reflecting the invalidity of the "cost-share theorem". This is supported by our results on the German and US Total Economies, whose service sectors did in fact increase over the considered time spans, as discussed in Lindenberger et al. (2017). Even in the service sector alone, using capital, labor, and (final) energy as factor inputs, the output elasticity of (final) energy may exceed energy's factor cost share in service production considerably (Lindenberger 2003). Hence the argument of Illig and Schindler (2017) that the "importance" of a sector may be associated with a decreasing output share during growth, and the invalidity of the factor input cost-share theorem, emphasized by us and others, are not at all contradictory.

The conceptual and methodological framework of growth accounting recalled in this article has not only been helpful for computing the impact of energy conversion on economic growth. It also provides means for computing the impact of entropy production - the ugly twin of energy conversion. For instance, Kümmel (2016) introduced the concepts of conventional output $Y_{\mathrm{C}}(K, L, E ; t)$, defined as the sum of goods and services not dedicated to abating the emissions that result from entropy production, and of loss $\Lambda_{m}(t)$, defined as the (monetary value of the) goods and services that are dedicated to emission mitigation of type $m$. The total output, which includes all goods and services, is described by the LinEx function $Y_{L 1}$ from Eq. (22). Thus,

$Y_{\mathrm{C}}(K, L, E ; t) \equiv Y_{L 1}(K, L, E ; t)-\Lambda(t)$, where $\Lambda \equiv \sum_{m} \Lambda_{m}(t)$.

A first attempt to calculate $\Lambda$ and $Y_{\mathrm{C}}(K, L, E ; t)$ exemplarily assumed that before some critical time $t_{\mathrm{C}}$ German society had not bothered about emission mitigation. Total output had been equal to the output consumers and investors had used for their conventional individual needs, so that $\Lambda\left(t<t_{\mathrm{C}}\right)=0$ and $Y_{\mathrm{C}}\left(K, L, E ; t<t_{\mathrm{C}}\right)=Y_{L 1}\left(K, L, E ; t<t_{\mathrm{C}}\right)$. However, at time $t_{\mathrm{C}}$ people realize the need to invest in new, unconventional economic activities that protect the environment. One 
of the options available is emission mitigation via energy conservation. In order to stimulate energy conservation in the industrial sector of the Federal Republic of Germany, energy taxation is introduced. Contrary to what had happened in reality, this starts in 1986.

Under simplifying, idealized thermodynamic assumptions, the potential of energy conservation had been computed by thermoeconomic optimization of the combination of heat exchanger networks $(e)$, heat pumps $(p)$, and cogeneration $(c)$. Under the constraint that the total cost of the energy system with energy taxation must not exceed the cost without energy taxation, Groscurth and Kümmel (1989) had found that a maximum reduction of the annual primary energy demand (by roughly 30\%) could be achieved by an energy tax that quintuples the aggregated energy price in 1986.

Now, if one disregards the positive effects energy taxation may have, provided the revenues from it are wisely used, the loss $\Lambda$ in Eq. (23) would be equal to the annual $\operatorname{cost} \Lambda_{\mathrm{epc}}$ of exhausting the energy saving potential completely. This $\Lambda_{\text {epc }}$ turns out to be about $6 \%$ of the total output $Y_{\mathrm{L} 1}\left(K, L, E ; t=t_{\mathrm{C}}=1986\right)$ in 1986. Based on this, one can also compute the number $\Phi<1$, which, multiplying LinEx output elasticities, transforms them into the elasticities of conventional output $Y_{\mathrm{C}}\left(K, L, E ; t \geq t_{\mathrm{C}}\right)$, with which society must get along, when emissions are mitigated by energy conservation. One finds $\Phi=0.91$. Of course, the model is crude. But it indicates what can be done in principle to include emission abatement in analyses of economic growth.

Similarly, one may calculate other future scenarios of economic growth. What one would need are reasonable (or bold) forecasts of technical innovations, political changes (like German reunification), and entrepreneurial decisions on investing in capital, labor, and energy.

\section{Summary}

The aggregation of output and capital in terms of work performance and information processing, and its mapping on monetary aggregation, puts the computation of economic growth by means of production functions on a consistent conceptual footing. All energy-dependent production functions must be twice differentiable and hence satisfy the corresponding set of differential equations. Non-neoclassical growth analyses with such production functions do not weigh capital, labor, and energy by their cost shares, but rather determine output elasticities econometrically. These analyses show that the production factor energy explains a substantial part of economic growth that had been attributed to unexplained "technological progress" by mainstream economics. The production functions involved have output elasticities that are for energy much larger and for labor much smaller than the cost shares of these factors. They may also serve for adjusting growth accounting to the cost of abating harmful emissions from energy conversion and entropy production.

Acknowledgements Open Access funding provided by Projekt DEAL. We thank two anonymous reviewers for their comments

\section{Compliance with Ethical Standards}

Conflict of interests On behalf of all authors, the corresponding author states that there is no conflict of interests.

Open Access This article is licensed under a Creative Commons Attribution 4.0 International License, which permits use, sharing, adaptation, distribution and reproduction in any medium or format, as long as you give appropriate credit to the original author(s) and the source, provide a link to the Creative Commons licence, and indicate if changes were made. The images or other third party material in this article are included in the article's Creative Commons licence, unless indicated otherwise in a credit line to the material. If material is not included in the article's Creative Commons licence and your intended use is not permitted by statutory regulation or exceeds the permitted use, you will need to obtain permission directly from the copyright holder. To view a copy of this licence, visit http://creativecommons.org/licenses/by/4.0/.

\section{References}

Ayres RU, Warr B (2001) Accounting for growth: the role of physical work. In: Max-Planck-Institute for Research into Economic Systems (ed) Proceedings of the workshop Reappraising Production Theory, Jena

Ayres RU, Warr B (2009) The economic growth engine. Edgar Elgar, Cheltenham

Ayres RU, Ayres LW, Warr B (2003) Exergy, power and work in the US economy, 1900-1998. Energy 28:219-273

Baehr HD (1964) Thermodynamik, (5. Aufl.), Springer, Berlin

Burger JR, Brown JH, Day JW Jr, Flanagan T, Roy ED (2019) The central role of energy in the urban transition: global challenges for sustainability. Biophys Econ Resour Qual 4:5. https://doi. org/10.1007/s41247-019-0053-Z

Eichhorn W, Henn R, Neumann K, Shepard RW (eds) (1982) Economic theory of natural resources. Physica-Verlag, Würzburg-Wien

Felipe J, Fisher JM (2003) Aggregation in production functions: what applied economists should know. Metroeconomica 54:208-262

Fix B (2019) The aggregation problem: implications for ecological and biophysical economics. Biophys Econ Resour Qual 4:1. https:// doi.org/10.1007/s41247-018-0051-6

Fricke J, Borst WL (1984) Energie, 2nd edn. Oldenbourg, München

Groscurth H-M, Kümmel R (1989) The cost of energy optimization: a thermoeconomic analysis of national energy systems. Energy 14:665-696

Heun MK, Santos J, Brockway PE, Pruim R, Domingos T, Sakai M (2017) From theory to econometrics to policy: cautionary tales for policy making using aggregate production functions. Energies 10:203. https://doi.org/10.3390/en10020203

Illig A, Schindler I (2017) Oil extraction, economic growth, and oil price dynamics. Biophys Econ Resour Qual 2:1. https://doi. org/10.1007/s41247-016-0016-6 
Kluge G, Neugebauer G (1993) Grundlagen der Thermodynamik. Spektrum Fachverlag, Heidelberg

Kümmel R (2011) The second law of economics: energy, entropy and the origins of wealth. Springer, New York

Kümmel R (2016) The impact of entropy production and emission mitigation on economic growth. Entropy 18:75. https://doi. org/10.3390/e18030075 (Open Access)

Kümmel R, Lindenberger D (2014) How energy conversion drives economic growth far from the equilibrium of neoclassical economics. New J Phys 16:125008. https://doi.org/10.1088/13672630/16/12/125008 (Open Access)

Kümmel R, Lindenberger D, Paech N (2018) Energie, Entropie, Kreativität: Was das Wirtschaftswachstum treibt und bremst. Springer, Berlin

Lindenberger D (2003) Service production functions. J Econ 80(2):127-143

Lindenberger D, Weiser F, Winkler T, Kümmel R (2017) Economic growth in the USA and Germany 1960-2013: the underestimated role of energy. Biophys Econ Resour Qual 2:10. https://doi. org/10.1007/s41247-017-0027-y

Meadows DH, Meadows DL, Randers J, Behrens WW III (1972) The limits to growth. Universe Books, New York

Proops JLR, Faber M, Wagenhals G (1993) Reducing $\mathrm{CO}_{2}$-emissions. Springer, Berlin
Reif F (1965) Fundamentals of statistical and thermal physics. McGRAW-Hill, New York

Robinson J (1953) The production function and the theory of capital. Rev Econ Stud 21:81-106

Robinson J (1971) The measurement of capital: the end of the controversy. Econ J 81:597-602

Solow RM (1957) Technical change and the aggregate production function. Rev Econ Stat 39:312-320

Solow RM (1994) Perspectives on growth theory. J Econ Perspect 8:45-54

Stresing R, Lindenberger D, Kümmel R (2008) Cointegration of output, capital, labor, and energy. Eur Phys J B 66:279-287

Ströbele W (1982) Growth models with restrictions concerning energy resources: an attempt to identify critical parameters and structural features. In: Eichhorn W, Henn R, Neumann K, Shepard RW (eds), pp 389-406

van Gool W (1998) Exergie en Energie. Van Gool ESE Consultancy, Driebergen

Publisher's Note Springer Nature remains neutral with regard to jurisdictional claims in published maps and institutional affiliations. 